\title{
Axial stent strut angle influences wall shear stress after stent implantation: analysis using 3D computational fluid dynamics models of stent foreshortening
} John F LaDisa Jr'1,2,5, Lars E Olson 5 , Douglas A Hettrick ${ }^{2,5}$,
David C Warltier $^{2,3,4,5}$, Judy R Kersten

Address: ${ }^{1}$ Department of Pediatrics (Division of Cardiology), Stanford University, Palo Alto, California, USA, ${ }^{2}$ Department of Anesthesiology, the Medical College of Wisconsin and the Clement J. Zablocki Veterans Affairs Medical Center, Milwaukee, Wisconsin, USA, ${ }^{3}$ Department of Medicine (Division of Cardiovascular Diseases), the Medical College of Wisconsin and the Clement J. Zablocki Veterans Affairs Medical Center, Milwaukee, Wisconsin, USA, ${ }^{4}$ Department of Pharmacology and Toxicology, the Medical College of Wisconsin and the Clement J. Zablocki Veterans Affairs Medical Center, Milwaukee, Wisconsin, USA and ${ }^{5}$ Department of Biomedical Engineering, Marquette University, Milwaukee, Wisconsin, USA

Email: John F LaDisa - jladisa@stanford.edu; Lars E Olson - lars.olson@marquette.edu; Douglas A Hettrick - doug.hettrick@medtronic.com; David C Warltier - warltier@mcw.edu; Judy R Kersten - jkersten@mcw.edu; Paul S Pagel* - pspagel@mcw.edu

* Corresponding author

Published: 26 October 2005

BioMedical Engineering OnLine 2005, 4:59 doi:10.1 186//475-925X-4-59
Received: 22 August 2005

Accepted: 26 October 2005

This article is available from: http://www.biomedical-engineering-online.com/content/4/I/59

(C) 2005 LaDisa et al; licensee BioMed Central Ltd.

This is an Open Access article distributed under the terms of the Creative Commons Attribution License (http://creativecommons.org/licenses/by/2.0), which permits unrestricted use, distribution, and reproduction in any medium, provided the original work is properly cited.

\begin{abstract}
Introduction: The success of vascular stents in the restoration of blood flow is limited by restenosis. Recent data generated from computational fluid dynamics (CFD) models suggest that the vascular geometry created by an implanted stent causes local alterations in wall shear stress (WSS) that are associated with neointimal hyperplasia $(\mathrm{NH})$. Foreshortening is a potential limitation of stent design that may affect stent performance and the rate of restenosis. The angle created between axially aligned stent struts and the principal direction of blood flow varies with the degree to which the stent foreshortens after implantation.
\end{abstract}

Methods: In the current investigation, we tested the hypothesis that stent foreshortening adversely influences the distribution of WSS and WSS gradients using time-dependent 3D CFD simulations of normal arteries based on canine coronary artery measurements of diameter and blood flow. WSS and WSS gradients were calculated using conventional techniques in ideal $(16 \mathrm{~mm})$ and progressively foreshortened ( 14 and $12 \mathrm{~mm}$ ) stented computational vessels.

Results: Stent foreshortening increased the intrastrut area of the luminal surface exposed to low WSS and elevated spatial WSS gradients. Progressive degrees of stent foreshortening were also associated with strut misalignment relative to the direction of blood flow as indicated by analysis of near-wall velocity vectors.

Conclusion: The current results suggest that foreshortening may predispose the stented vessel to a higher risk of neointimal hyperplasia. 


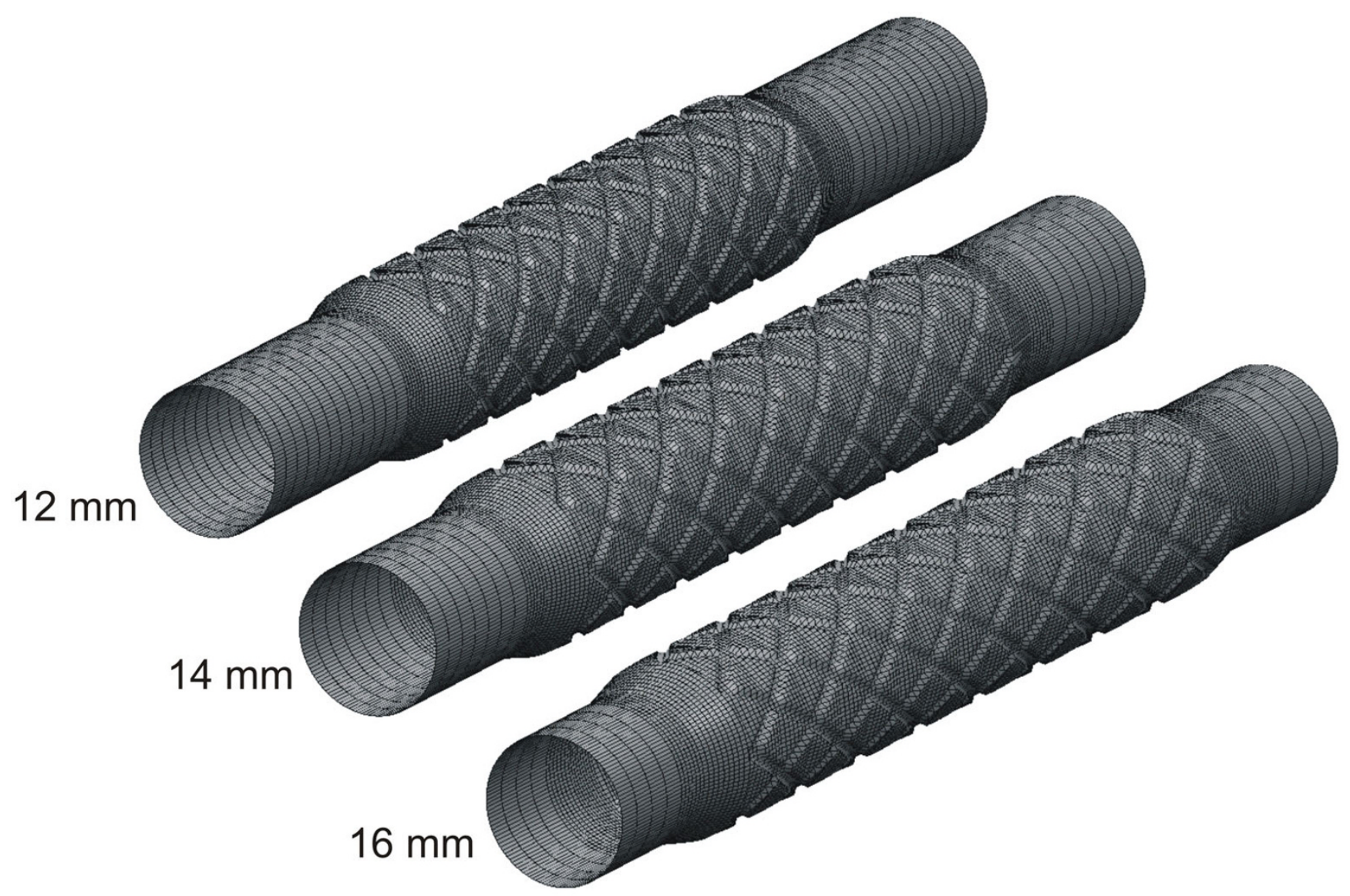

Figure I

Computational vessels implanted with 12, 14 or $16 \mathrm{~mm}$ stents consisting of 8 axial and circumferential repeating strut sections that were deployed using a stent-to-artery diameter convention of 1.2 to I. The diameter of the native vessel for all simulations was $2.74 \mathrm{~mm}$. The computational vessel implanted with the $16 \mathrm{~mm}$ stent was designated as the ideal stent length after implantation and the 14 and $12 \mathrm{~mm}$ stents represent progressive degrees of foreshortening.

\section{Introduction}

Stents are commonly used to treat coronary and peripheral vascular stenoses, but restenosis after implantation remains a persistent problem. The mechanisms responsible for restenosis have yet to be clearly elucidated $[1,7,14]$. Many stent designs are currently used in the clinical setting, and each of these designs has unique geometric and mechanical properties $[5,13,36]$. A correlation between stent geometry and the severity of subsequent neointimal hyperplasia has been described in animal models and humans $[14,35,37,44]$. We recently demonstrated that the number, width and thickness of stent struts and the deployment diameter and scaffolding created by an implanted stent substantially affects the area of the stented zone subjected to low wall shear stress (WSS) using time-dependent 3D computational fluid dynamics modeling $[23,24]$. We have also recently shown that these areas of low WSS predict subsequent development of neointimal hyperplasia in vivo[25].
Foreshortening (the difference between the desired and actual stent length after deployment) is a potential limitation of stent design that may affect stent performance and the rate of restenosis. The deployment of all types of stents is associated with deformation of struts about specific vertices within each stent mesh. Foreshortening varies with stent morphology because of differential deformation of interconnected struts during deployment $[2,40]$. The angle created between axially aligned stent struts and the principal direction of blood flow varies with the degree to which the stent foreshortens after implantation. Thus, theoretically deleterious variations in WSS distribution may occur in stent designs that demonstrate substantial degrees of foreshortening. A previous study demonstrated that strut angle influences cellular adhesion in vitro[12]. These data suggest that changes in strut angle resulting from foreshortening contribute to an altered flow environment that may be conducive to restenosis. In the current investiga- 


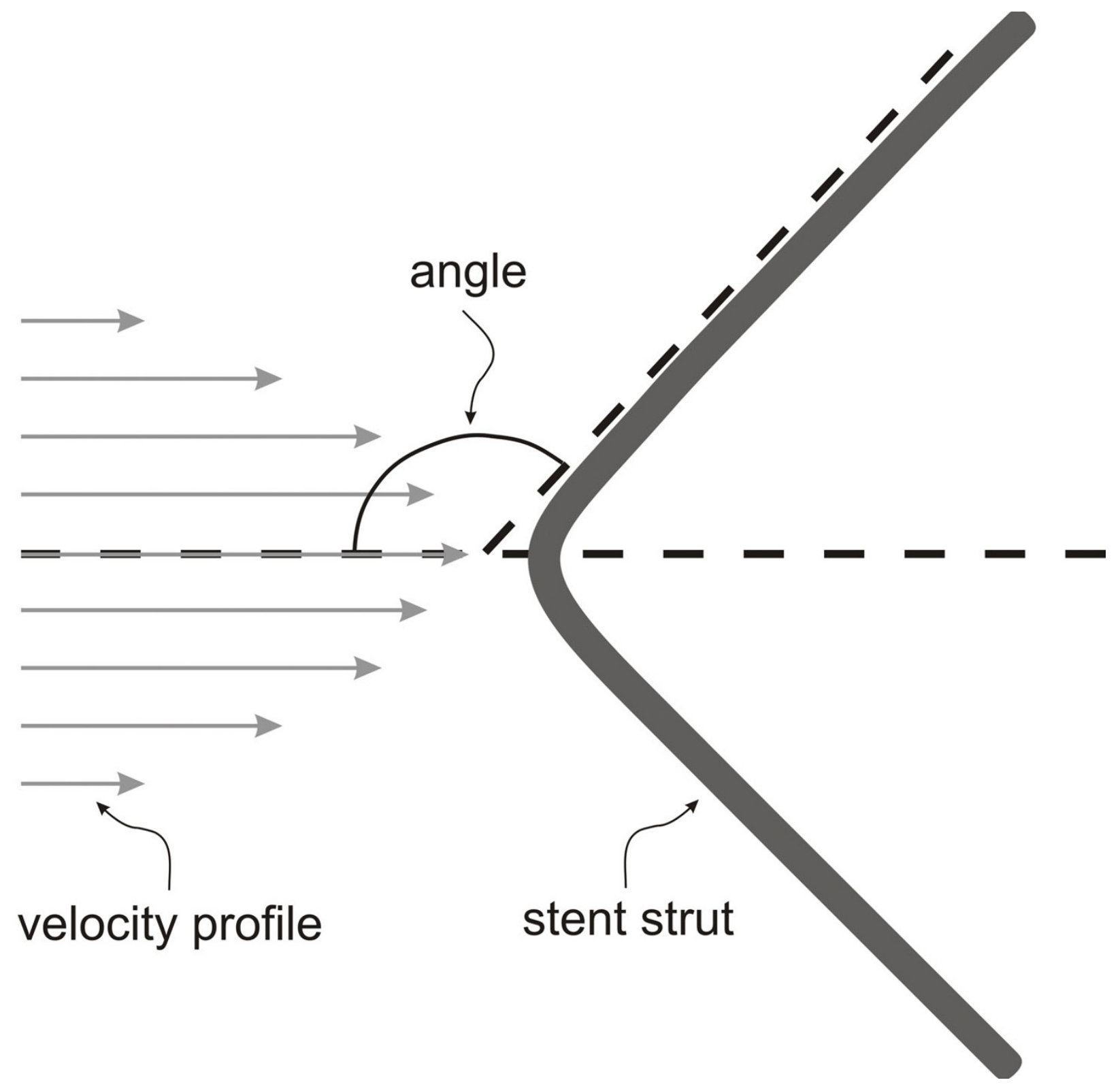

Figure 2

Schematic illustration demonstrating measurement of the stent strut angle with respect to the primary direction of blood flow.

tion, we tested the hypothesis that foreshortening adversely influences the distribution of WSS and WSS gradients previously implicated in neointimal hyperplasia using 3D computational fluid dynamics models.

\section{Methods}

\section{Construction of stented computational vessels}

A custom automated geometric construction and mesh generation algorithm was used to construct idealized computational arteries containing a slotted-tube stent embedded within a normal unstented computational ves- sel based on blood flow and diameter measurements obtained from canine left anterior descending coronary arteries[21]. The algorithm allows for the alteration of several geometric parameters including the stent length and diameter relative to that of the unstented portions of the computational vessel. The thickness and width of all stent struts were 0.096 and $0.197 \mathrm{~mm}$, respectively. All computational vessels were composed of structured hexahedral control volumes arranged in a three-domain butterfly design that exploited symmetric stent and vessel properties to model one-fourth of the computational vessel. 


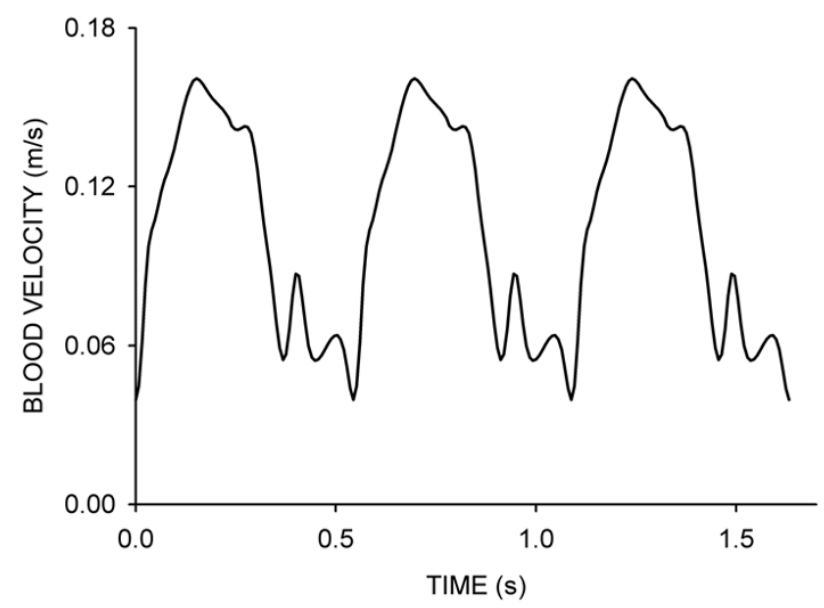

Figure 3

Blood flow velocity waveform measured in the proximal portion of a canine left anterior descending coronary artery and used for the time-dependent simulations conducted in the current investigation.

Three time-dependent simulations were performed in total. Computational vessels were created consisting of 8 axial and circumferential repeating strut sections that were deployed using a stent-to-artery diameter ratio of 1.2 to 1 (Figure 1). The diameter of the unstented portions of the computational vessels for all simulations was $2.74 \mathrm{~mm}$. The computational vessel within the stented region conformed to the geometry of the implanted stent as previously documented $[3,7,11,31]$. The length of the computational stents were 12,14 or $16 \mathrm{~mm}$ where $16 \mathrm{~mm}$ represents the ideal stent length after implantation and the 14 and $12 \mathrm{~mm}$ stents represent progressive degrees of foreshortening, respectively. The amount of foreshortening used in the current models ( 12 to $25 \%$ ) is consistent with stent foreshortening observed clinically $[6,16]$. The stent strut angles with respect to the primary direction of blood flow were $151^{\circ}, 146^{\circ}$ and $141^{\circ}$, for the 16,14 and $12 \mathrm{~mm}$ stents, respectively. Maintaining the same number of axial and circumferential repeating strut units throughout each simulation facilitated the study of flow disturbances produced by this stent strut orientation angle with respect to the primary direction of blood flow (Figure 2).

\section{Computational model simulations}

Simulations were performed using the commercially available software package CFD-ACE (CRDRC; Huntsville, AL, http://www.cfdrc.com). This software uses a finite volume approach to solve the Navier-Stokes equations at the center of each hexahedral control volume. Theoretical arteries were subjected to a blood flow velocity waveform obtained from a canine coronary artery under normal resting conditions (Figure 3). A plug flow velocity profile was imposed at the inlet of each vessel and additional length was added to all arteries to allow for fully developed flow $[10,23]$. An initial axial velocity of $0.105 \mathrm{~m} / \mathrm{s}$ was imposed within the fluid domain at the start of each simulation to avoid a "cold start" and increase the likelihood of convergence. A zero pressure boundary condition was imposed at the outlet of the computational vessels. Simulations were conducted using a backward Euler temporal differencing method to investigate time-dependent changes in indices of WSS within the stented portion of each vessel. Computational simulations were conducted assuming a Newtonian, incompressible fluid with a density of $1.06 \mathrm{~g} / \mathrm{cm}^{3}$ and viscosity of $3.7 \mathrm{cP}$. The Reynolds and Womersley numbers for all of the simulations were approximately 105 and 2.91, respectively.

\section{Determination of wall shear stress indices}

Wall shear stress was determined as the product of viscosity and shear rate. A detailed discussion of this calculation is presented elsewhere[24]. Briefly, the CFD-ACE flow solver calculates shear rate during incompressible flow using the second invariant of the strain rate tensor. Thus, shear rate $(\dot{\gamma})$ was determined as $\dot{\gamma}=\left[2\left\{(\partial u / \partial x)^{2}+(\partial v / \partial y)^{2}+(\partial w / \partial z)^{2}\right\}+(\partial u / \partial y+\partial v / \partial x)^{2}+(\partial u / \partial z+\partial w / \partial x)^{2}+(\partial v / \partial z+\partial w / \partial y)^{2}\right]^{1 / 2}$ where $u, v$, and $w$ are the $x, y$ and $z$ components of velocity vector, $\mathbf{u}$, respectively.

This definition accounts for pure shear as well as extensional or elongational deformation in the flow domain.

Spatial wall shear stress gradients (WSSG) were calculated during post-processing as discussed previously[15,23]. WSSG was used to quantify the influence of non-uniform hemodynamic forces on adjacent intravascular cells. Previous studies have suggested that this spatial WSS inhomogeneity may correlate with the location of neointimal hyperplasia in vivo $[4,38,39]$ as was recently observed following chronic stent implantation into rabbit iliac arteries[25]. Frictional forces that act predominantly in axial and circumferential directions were most likely to cause expansion of intracellular gaps and disrupt intracellular junctions[28]. As a result, WSSG was calculated as $\left[\left(\frac{\partial \tau_{w, z}}{\partial z}\right)^{2}+\left(\frac{\partial \tau_{w, \theta}}{\partial \theta}\right)^{2}\right]^{1 / 2}$, where $\tau_{w}$ is the WSS in the axial $(z)$ and circumferential $(\theta)$ directions, respectively. WSSG observed overlying stent struts were excluded from the current analysis because these areas do not acutely contain biologically active tissue immediately after acute stent implantation. 


\section{Quantification of simulation results}

The threshold for comparing distributions of low WSS between simulations was established at 5 dynes $/ \mathrm{cm}^{2}$ for comparison to previous work $[23,24]$ and because vascular regions subjected to WSS below this value have been shown to strongly correlate with sites of intimal thickening $[17,18]$. Regions of low WSS were also expressed as percentages of the stent area within intrastrut regions in the proximal, middle and distal portions of the stent in order to determine perturbations produced by foreshortening and stent strut orientation. Near-wall velocity vectors were also visualized at spatial locations in the proximal, middle and distal portions of the stent to observe the behavior of blood flow in these regions.

WSSG have also been used previously to examine the hypothesis that normally confluent cells react to nonuniform distributions of WSS in a way that promotes neointimal hyperplasia[9,32,38]. The percentage of the vessel wall subjected to WSSG values above 20 dynes $/ \mathrm{cm}^{3}$ was quantified and compared between simulations in the current investigation. WSSG of this order of magnitude previously correlated with areas of neointimal hyperplasia in the toe region of an end-to-side arterial anastomo$\operatorname{sis}[19,27,32]$.

\section{Results}

\section{Mesh and time-step independence}

Multiple simulations were performed to investigate spatial mesh independence. The spatial mesh density was four times greater in stented as compared to unstented regions of the computational vessels resulting in approximately 250,000 nodes per quarter of each computational artery. Results were considered to be spatially independent of the computational mesh when differences in the distributions of WSS were less than $6 \%$ between successive mesh densities[20,30]. Simulations were performed on a Dell Optiplex GX270 $2.4 \mathrm{GHz}$ workstation with 2 Gbyte of RAM that enabled convergence of simulations at a rate of approximately 25 time-steps per day. Time-step independence was examined by subjecting computational vessels to the coronary artery blood flow velocity waveform illustrated in Figure 3 using time-step increments of $10.9,8.0$ or $5.4 \mathrm{~ms}$. Three consecutive cardiac cycles were allowed to reach simulation convergence, and distributions of WSS were compared at equivalent points during each cardiac cycle and between waveform permutations. The results demonstrated that a single cardiac cycle was sufficient to allow for the evolution of initial conditions, and simulation results became periodic shortly after the first cardiac cycle. A time step increment of $8.0 \mathrm{~ms}$ was sufficient to resolve temporal distributions of WSS within the stented and unstented regions of each vessel.

\section{Simulation results}

Indices of WSS corresponding to the mean blood flow velocity during the cardiac cycle are shown in Table 1. Lower WSS was observed within the stented region of all simulations, and stagnation zones occurred around stent struts. The percentage of intrastrut area exposed to distributions of WSS $<5$ dynes $/ \mathrm{cm}^{2}$ was greatest in the proximal portion of each stent independent of length and strut orientation (Table 1). These intrastrut areas of low WSS were least pronounced in the distal portion of the stents. The percentage of intrastrut area exposed to WSS $<5$ dynes $/ \mathrm{cm}^{2}$ within a particular intrastrut region decreased as the length of the stent increased. Conversely, the total area of the stent exposed to WSS $<5$ dynes $/ \mathrm{cm}^{2}$ increased as the stent length increased. However, when normalized by the length of the stent, the percentage of the computational vessel subjected to WSS $<5$ dynes $/ \mathrm{cm}^{2}$ modestly increased with the degree of foreshortening ( 0.78 as compared to $0.71 \mathrm{~mm}^{2}$ for 16 and $12 \mathrm{~mm}$ stents, respectively).

The total area of the computational vessel subjected to WSSG greater than 20 dynes $/ \mathrm{cm}^{3}$ increased as the stent length increased (67.4 versus 89.3 dynes $/ \mathrm{cm}^{3}$ for 12 and $16 \mathrm{~mm}$ stents, respectively). In addition, the maximum WSSG observed throughout the stented region decreased as stent length increased $\left(395,293\right.$ and 248 dynes $/ \mathrm{cm}^{3}$ for the 12,14 and $16 \mathrm{~mm}$ stents, respectively). When normalized by the length of the stent, the portion of vessels subjected to elevated WSSG was similar for each computational vessel simulation (Table 1).

Value-weighted near-wall velocity vectors in the first proximal, middle and last distal repeating stent unit resulting from the unique strut orientation of each of the stents are illustrated in Figure 4. Reductions in the size of the vectors in the proximal as compared to the middle region resulted from the increase in luminal diameter within the stented region and account for the pronounced low WSS found in the proximal portion of the computational stent in all simulations. Adjacent blood layers appear to converge before entering each repeating stent unit and diverge after entering each axial diamond. This divergence accounted for reductions in WSS adjacent to stent struts. Figure 4 also demonstrates that the $12 \mathrm{~mm}$ stent foreshortening simulation produced large deviations in value-weighted nearwall velocity vectors adjacent to stent struts, in contrast to the observations with computational stents deployed to an ideal length of $16 \mathrm{~mm}$.

Time-dependent alterations in the spatial distributions of WSS throughout the cardiac cycle are illustrated in Figure 5. Stagnation regions observed adjacent to stent struts developed immediately before blood flow deceleration at the local and global maxima of the flow waveform (rows 2, 4 and 6). These stagnation regions were more pro- 
Table I: Stent properties and indices of wall shear stress

\begin{tabular}{|c|c|c|c|}
\hline Stent Length $(\mathrm{mm})$ & 16 & 14 & 12 \\
\hline Luminal surface area covered by the stent (\%) & 24 & 22 & 19 \\
\hline Stent strut angle with respect to primary flow direction $\left(^{\circ}\right)$ & 151 & 146 & $|4|$ \\
\hline Proximal Intrastrut WSS $<5$ dynes $/ \mathrm{cm}^{2}(\%)$ & 48 & 52 & 55 \\
\hline Middle Intrastrut WSS < 5 dynes $/ \mathrm{cm}^{2}(\%)$ & 18 & 46 & 50 \\
\hline Distal Intrastrut WSS $<5$ dynes $/ \mathrm{cm}^{2}(\%)$ & 12 & 21 & 48 \\
\hline Total area exposed to WSS $<5$ dynes $/ \mathrm{cm}^{2}\left(\mathrm{~mm}^{2}\right)$ & 117 & 111 & 96.8 \\
\hline Total area exposed to WSSG $>20$ dynes $/ \mathrm{cm}^{3}\left(\mathrm{~mm}^{2}\right)$ & 89.3 & 72.5 & 67.4 \\
\hline Normalized area exposed to WSS $<5$ dynes $/ \mathrm{cm}^{2}$ & 0.71 & 0.77 & 0.78 \\
\hline Normalized area exposed to WSSG $>20$ dynes $/ \mathrm{cm}^{3}$ & 0.54 & 0.50 & 0.54 \\
\hline WSSG $_{\max }\left(\right.$ dynes $\left./ \mathrm{cm}^{3}\right)$ & 248 & 293 & 395 \\
\hline
\end{tabular}

Abbreviations: WSS = wall shear stress; WSSG = wall shear stress gradient

nounced in the 12 and $14 \mathrm{~mm}$ computational stents as compared to the $16 \mathrm{~mm}$ simulation.

\section{Discussion}

Increasing evidence suggests that the geometry and physical properties of a deployed stent may influence the local blood flow environment and alter distributions of WSS after implantation, thereby rendering certain areas of the vessel wall more susceptible to neointimal hyperplasia and subsequent restenosis[11,29,31,43]. Our laboratory has previously demonstrated that the number, width and thickness of strut struts, the stent-to-artery deployment diameter, and stent scaffolding influence the area of a vessel exposed to low WSS and elevated spatial and temporal WSSG using computational fluid dynamics models generated from measured in vivo data[20,23,24]. These results suggested that stent geometry profoundly affects fluid dynamics that correlate with the spatial and temporal localization of neointimal hyperplasia as we recently reported using a combined approach of chronic iliac artery stent implantation in vivo, microfocal x-ray CT imaging, computational fluid dynamics and vascular histology[22,25,26].

The current results confirm and extend our previous observations and further demonstrate the importance of stent geometry on intravascular fluid dynamics. The current findings with $3 \mathrm{D}$ computational fluid dynamics modeling demonstrate that stent foreshortening increases the area of the luminal surface exposed to low WSS and elevated spatial WSSG. These data strongly suggest that stent foreshortening may precipitate more pronounced development of neointimal hyperplasia as compared to a stent deployed to its ideal length. This hypothesis remains to be tested in vivo, however. The angle created between axially aligned stent struts and the principal direction of blood flow varied with the deployed stent length. The current results using computational foreshortened stents and those deployed to their ideal length demonstrate that struts of the foreshortened stents were progressively mis- aligned with the direction of blood flow. This strut misalignment within the flow domain also substantially influenced the behavior of near-wall velocity vectors and contributed to the observed increases in deleterious distributions of WSS and WSSG in foreshortened as compared to ideal computational stent architecture. Stent foreshortening effectively increases the number of struts per unit length of a vessel, and we have previously demonstrated that such an increase in strut number is associated with greater exposure of the luminal surface to low WSS and elevated WSSG[23]. These previous and current observations are consistent with the intuitive notion that optimal stent design should assure that the vast majority of struts are aligned more parallel to blood flow in order to minimize changes in laminar blood flow characteristics and WSS distributions.

Although the normalized luminal area exposed to WSS < 5 dynes $/ \mathrm{cm}^{2}$ was similar for each of the stents computationally modeled in the current investigation, it is important to consider which of the parameters reported in Table 1 are most likely to influence the local cellular response and be associated with neointimal hyperplasia. The table clearly indicates that the angle of stent struts with respect to the primary flow direction strongly influences the intrastrut area of the vessel wall exposed to low WSS. Cells in these pronounced areas of low WSS are more likely to participate in the neointimal response. Normalizing the total area of the vessel exposed to low WSS by the length provides a less sensitive indication of the local impact on cells within the stented region that are likely to contribute to neointimal hyperplasia.

The current results require interpretation within the constraints of several potential limitations. Stents were implanted in idealized computational representations of healthy vessels and the results would likely differ if the study was performed using computational models of vascular disease. From a clinical perspective, stent diameter typically increases with the degree of foreshortening. Such 

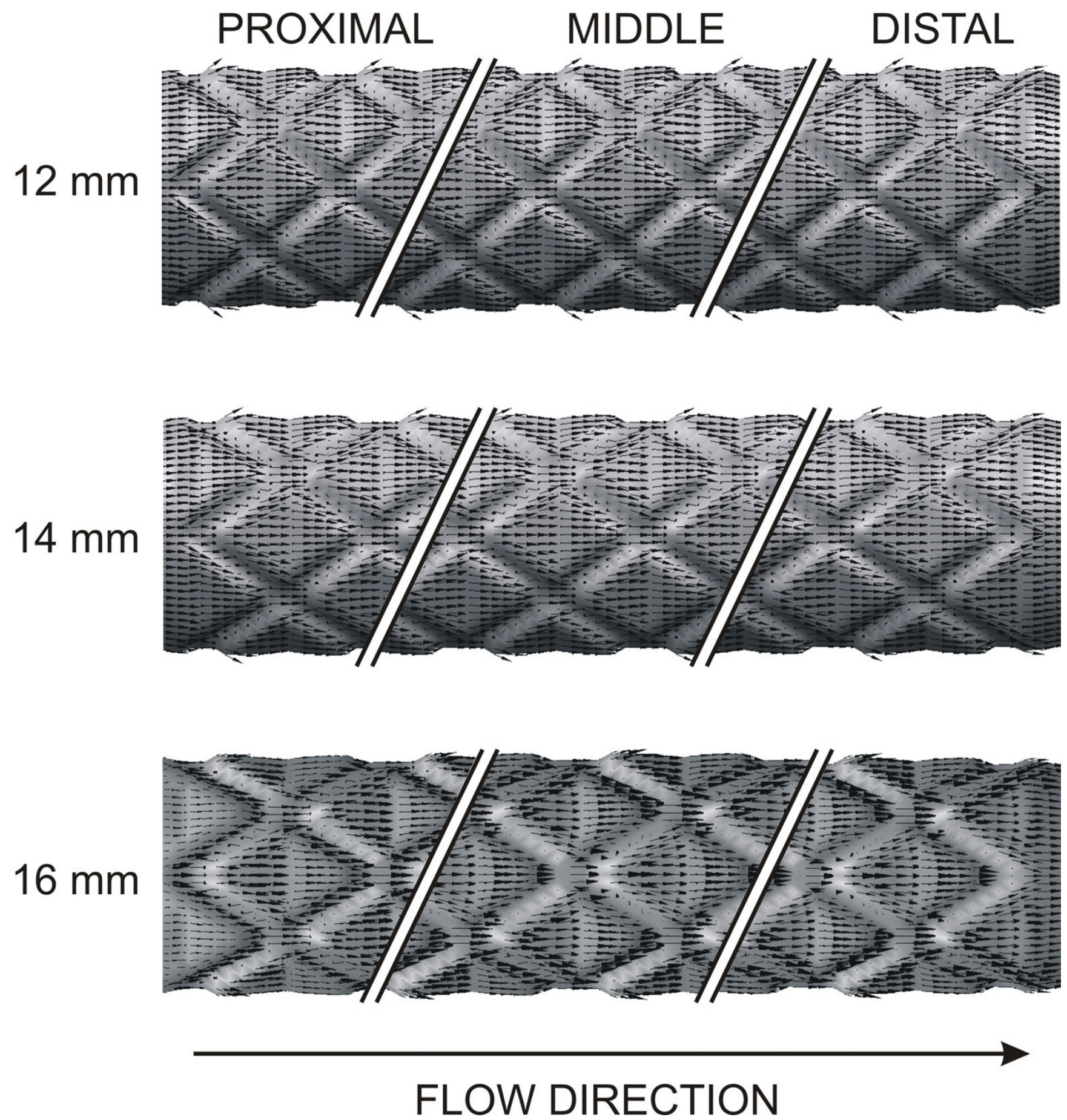

Figure 4

Value-weighted near-wall velocity vectors in the proximal, middle and distal portions of the stent resulting from the unique strut orientation angles corresponding to ideal $(16 \mathrm{~mm})$ and progressively foreshortened stents (14 and I2 mm). 

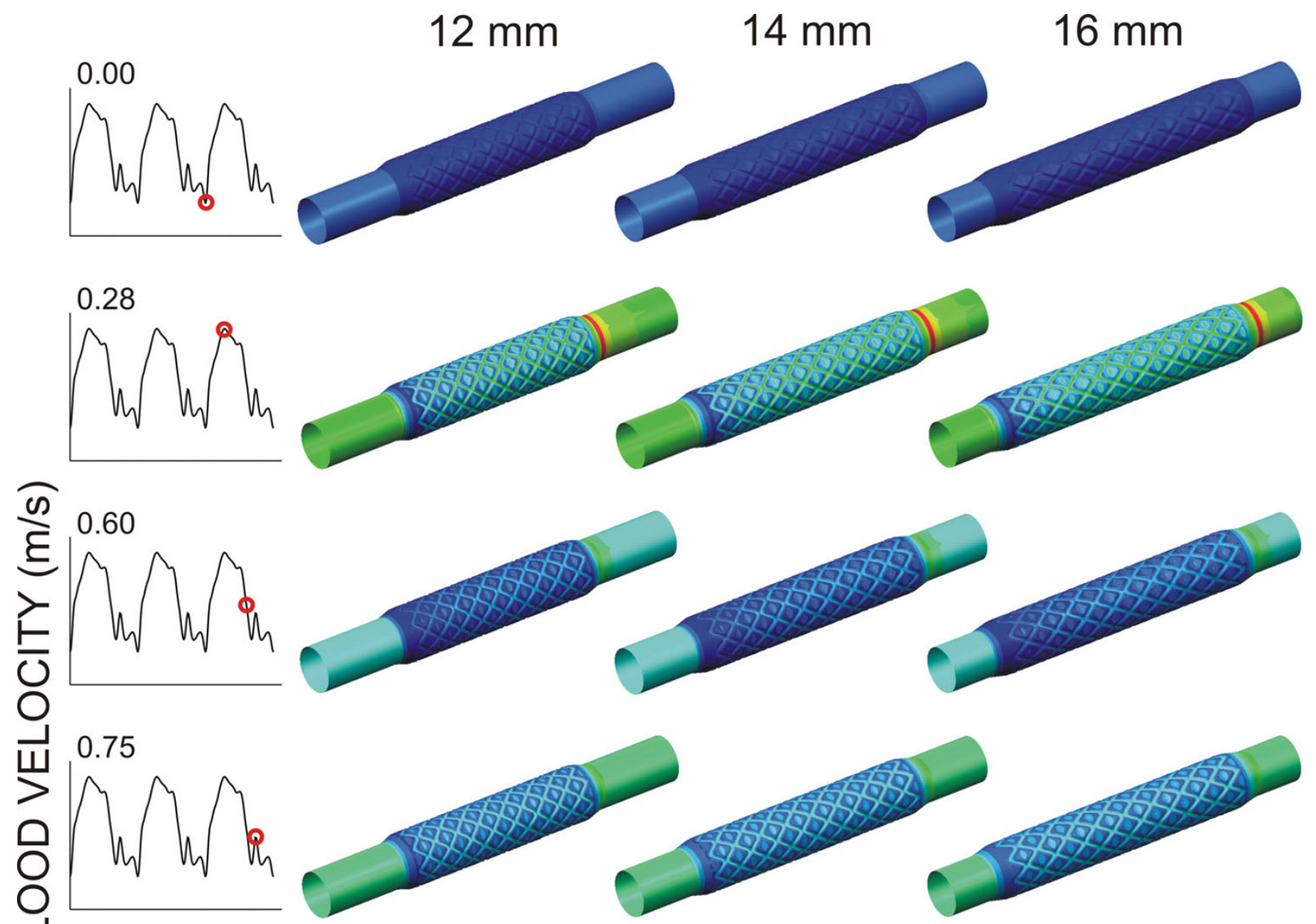

$\overrightarrow{\mathrm{m}}$
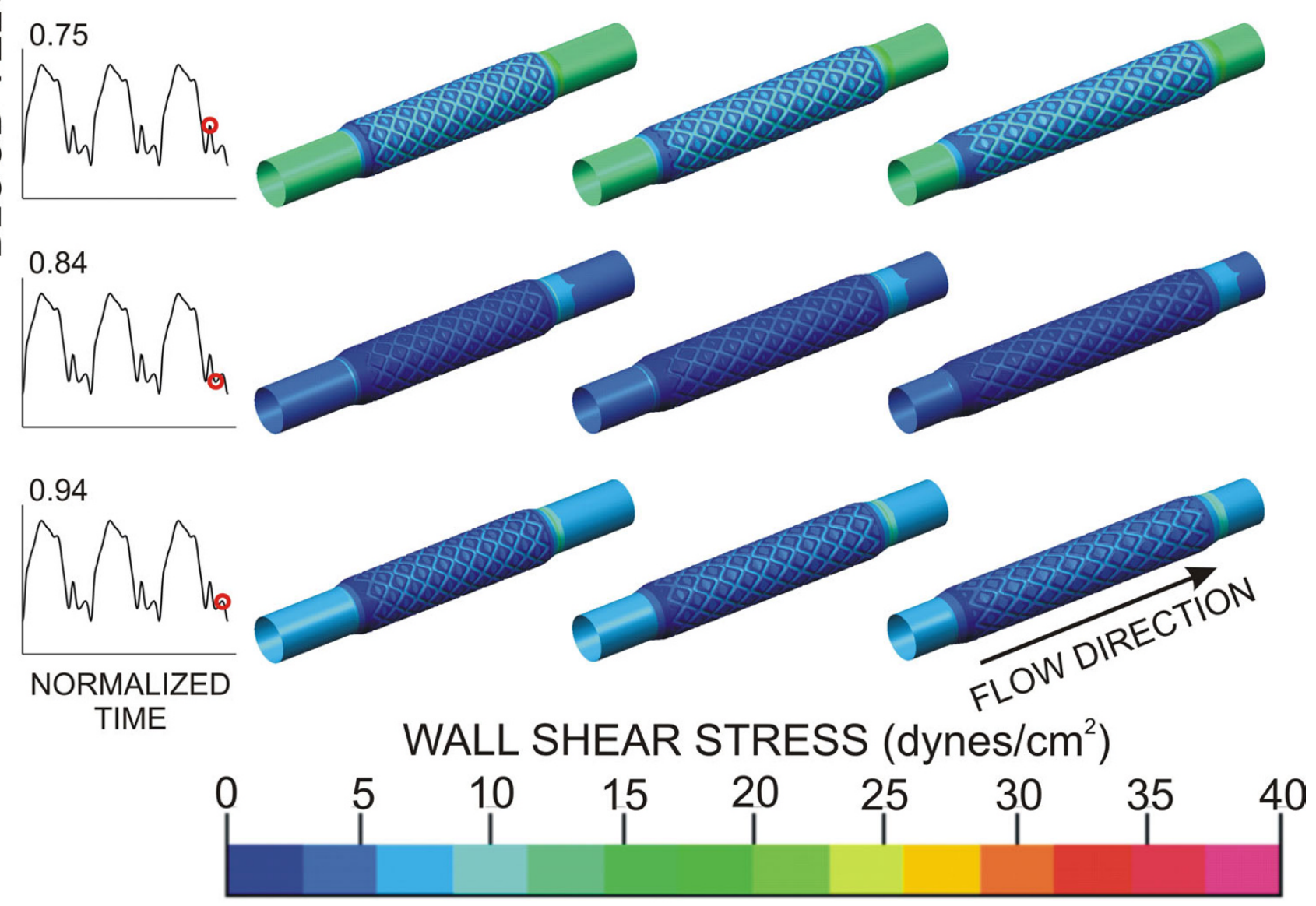

\section{Figure 5}

Time-dependent alterations in spatial wall shear stress throughout the cardiac cycle in ideal stents $(16 \mathrm{~mm})$ and those with progressive degrees of foreshortening (14 and $12 \mathrm{~mm}$ ). 
an increase in stent diameter would be expected to intrinsically produce a reduction in blood velocity, and hence WSS, within the stented region. We conducted the current investigation using a consistent diameter within the stented region of each computational vessel in order to isolate the influence of the incident strut angle on indices of WSS independent of changes in vessel diameter. As a result, the current results may actually underestimate the relative amount of the computational vessels subjected to low WSS and elevated spatial WSSG as a result of this observed clinical increase in diameter often associated with foreshortening. The current investigation was conducted using a rigid-wall approximation and a simplified outlet boundary condition. Previous studies have demonstrated that implantation of $16 \mathrm{~mm}$ slotted-tube stents into canine epicardial coronary arteries in vivo reduced vessel compliance to zero within the stented region[21] and that wall deformability does not greatly alter the velocity field under normal conditions[34]. Nevertheless, the results may differ from those observed clinically as a result of arterial compliance proximal and distal to the stented region and the ability of the distal vasculature to vasodilate in response to local metabolic need, thus altering the upstream resistance through the stented segment.

The potential clinical applicability of the current results in lieu of the widespread use of drug-eluting stents to treat vascular stenoses also deserves comment. Recent reviews suggested that drug-eluting stents may simply delay restenosis, but do not facilitate healing of the intima that is damaged by prior vascular disease or the stent implantation procedure. Thus, restenosis rates with drug-eluting stent may ultimately be similar to bare metal stents[8,33,41,42]. Moreover, this drug-eluting technology may not be applicable to all patient populations and locations within the arterial vasculature[8,33]. The current results further support the hypothesis that local flow patterns created by the stent should also be considered during stent design so as to minimize indices of fluid dynamics implicated in neointimal hyperplasia and to avoid the use of exogenous cytotoxic or antiproliferative agents.

\section{Conclusion}

In summary, the current results using 3D computational fluid dynamics modeling indicate that foreshorteninginduced orientation of stent struts with respect to the direction of blood flow is associated with increases in the area of the vessel subjected to low WSS and high WSSG, factors that have been previously correlated with subsequent neointimal hyperplasia in vivo. The change in incident strut angle with respect to the predominant flow direction was modest between modeled foreshortened as compared to ideal computational stents (141 to $151^{\circ}$ ), but increasing the degree of foreshortening reduced the axial alignment angle of stent struts and produced greater intrastrut areas of low WSS and elevated WSSG. Stent geometries that successfully restore distal perfusion but produce the least disruption to the native flow environment may ultimately provide maximum chronic vessel patency.

\section{Authors' contributions}

JFL planned and conducted the experiments from which the blood flow and diameter measurements used in the current investigation were obtained, created the automated geometric construction and mesh generation algorithm, formulated fluid dynamics models, conducted simulations and wrote drafts of the manuscript. LEO assisted with the formulation of fluid dynamics models, planning and completion of simulations, and helped with data analysis. DAH assisted in the design of the computational investigation, formulated fluid dynamics models, and helped with data analysis. JRK assisted in data analysis and critical revisions of manuscript. DCW also assisted in data analysis and critical revisions of the manuscript. PSP critically reviewed the design of the computational study and experiments from which the measurements used in the current investigation were obtained, fluid dynamics theory, and analysis of results and also provided multiple critical revisions of several drafts of the manuscript, including the final submitted manuscript. All authors read and agreed to the submission of the manuscript in its current form.

\section{Acknowledgements}

The authors would like to recognize David A. Schwabe and John P. Tessmer for their experimental support, Mary Lorence-Hanke for assistance in the preparation of this manuscript (Department of Anesthesiology, Medical College of Wisconsin), and Max Imas (Olin Engineering Center, Marquette University) and Juan Santiago and Rajiv Bharadwaj (Microfluidics Laboratory, Stanford University Department of Mechanical Engineering) for their technical and computational support. This work was supported in part by a Sigma Xi Grants-in-Aid of Research Award (to Dr. LaDisa) and by National Institutes of Health grants HL-03690 (to Dr. Kersten), HL-063705 (to Dr. Kersten), HL-054820 (to Dr. Warltier), and GM-008377 (to Dr. Warltier) from the United States Public Health Service, Bethesda, Maryland.

\section{References}

I. Bennett MR, O'Sullivan M: Mechanisms of angioplasty and stent restenosis: implications for design of rational therapy. Pharmacology \& Therapeutics 2001, 9 I: 149-166.

2. Farb A, Weber DK, Kolodgie FD, Burke AP, Virmani R: Morphological predictors of restenosis after coronary stenting in humans. Circulation 2002, I 05:2974-2980.

3. Kastrati A, Mehilli J, Dirschinger J, Pache J, Ulm K, Schuhlen H, Seyfarth M, Schmitt C, Blasini R, Neumann FJ, Schomig A: Restenosis after coronary placement of various stent types. Am J Cardiol 2001, 87:34-39.

4. Duda SH, Wiskirchen J, Tepe G, Bitzer M, Kaulich TW, Stoeckel D, Claussen CD: Physical properties of endovascular stents: an experimental comparison. Journal of Vascular and Interventional Radiology 2000, I I:645-654.

5. Kalmar G, Hubner F, Voelker W, Hutzenlaub J, Teubner J, Poerner T, Suselbeck T, Borggrefe M, Haase KK: Radial force and wall apposition of balloon-expandable vascular stents in eccentric 
stenoses: an in vitro evaluation in a curved vessel model. Journal of Vascular and Interventional Radiology 2002, 13:499-508.

6. Roguin $A$, Beyar $R$ : beStent--the serpentine balloon expandable stent: review of mechanical properties and clinical experience. Artificial Organs 1998, 22:243-249.

7. Rogers C, Edelman ER: Endovascular stent design dictates experimental restenosis and thrombosis. Circulation 1995 , 91:2995-3001

8. Schulz C, Herrmann RA, Beilharz C, Pasquantonio J, Alt E: Coronary stent symmetry and vascular injury determine experimental restenosis. Heart 2000, 83:462-467.

9. Yoshitomi Y, Kojima S, Yano M, Sugi T, Matsumoto Y, Saotome M, Tanaka K, Endo M, Kuramochi M: Does stent design affect probability of restenosis? A randomized trial comparing Multilink stents with GFX stents. Am Heart / 200I, |42:445-45।.

10. LaDisa JFJ, Olson LE, Guler I, Hettrick DA, Audi SH, Kersten JR, Warltier DC, Pagel PS: Stent design properties and deployment ratio influence indexes of wall shear stress: a three-dimensional computational fluid dynamics investigation within a normal artery. J Appl Physiol 2004, 97:424-430.

II. LaDisa JFJ, OIson LE, Guler I, Hettrick DA, Kersten JR, Warltier DC, Pagel PS: Circumferential vascular deformation after stent implantation alters wall shear stress evaluated using timedependent 3D computational fluid dynamics models. Journa of Applied Physiology 2005, 98:947-957.

12. LaDisa JF], Olson LE, Molthen RC, Hettrick DA, Pratt PF, Hardel MD, Kersten JR, Warltier DC, Pagel PS: Alterations in wall shear stress predict sites of neointimal hyperplasia after stent implantation in rabbit iliac arteries. Am J Physiol Heart Circ Physiol 2005, 288: H2465-75.

13. Verstandig AG, Bloom Al, Sasson T, Haviv YS, Rubinger D: Shortening and migration of Wallstents after stenting of central venous stenoses in hemodialysis patients. Cardiovascular and Interventional Radiology 2003, 26:58-64.

14. Choussat R, Black AJ, Bossi I, Joseph T, Fajadet J, Marco J: Long-term clinical outcome after endoluminal reconstruction of diffusely degenerated saphenous vein grafts with less-shortening wallstents. Journal of the American College of Cardiology 2000, 36:387-394.

15. Hamuro M, Palmaz JC, Sprague EA, Fuss C, Luo J: Influence of stent edge angle on endothelialization in an in vitro model. Journal of Vascular and Interventional Radiology 200 I, I 2:607-6 I I.

16. LaDisa JFJ, Hettrick DA, Olson LE, Guler I, Gross ER, Kress TT, Kersten JR, Warltier DC, Pagel PS: Coronary stent implantation alters coronary artery hemodynamics and wall shear stress during maximal vasodilation. J Appl Physiol 2002, 93:1939-1946.

17. Danenberg HD, Welt FG, Walker M, Seifert P, Toegel GS, Edelman ER: Systemic inflammation induced by lipopolysaccharide increases neointimal formation after balloon and stent injury in rabbits. Circulation 2002, 105:2917-2922.

18. Garasic JM, Edelman ER, Squire JC, Seifert P, Williams MS, Rogers C: Stent and artery geometry determine intimal thickening independent of arterial injury. Circulation 2000, 101:8I2-8I8.

19. Newman VS, Berry JL, Routh WD, Ferrario CM, Dean RH: Effects of vascular stent surface area and hemodynamics on intimal thickening. I Vasc Interv Radiol 1996, 7:387-393.

20. Kreutzer J, Rome J]: Open-cell design stents in congenital heart disease: a comparison of IntraStent vs. Palmaz stents. Catheter Cardiovasc Interv 2002, 56:400-409.

21. Ebeid MR: Balloon expandable stents for coarctation of the aorta: review of current status and technical considerations. Images in Pediatric Cardiology 2003, I 5:25-4I.

22. Fox RW, McDonald AT: Introduction to Fluid Mechanics. 4th edition. New York, John Wiley \& Sons, Inc.; 1992:322.

23. Kleinstreuer C, Hyun S, Buchanan JR, Longest PW, Archie JP, Truskey GA: Hemodynamic parameters and early intimal thickening in branching blood vessels. Crit Rev Biomed Eng 200I, 29:।-64.

24. DePaola N, Gimbrone MAJ, Davies PF, Dewey CF: Vascular endothelium responds to fluid shear stress gradients. Arterioscler Thromb 1992, I 2: | 254- I257.

25. Tada S, Tarbell JM: Flow through internal elastic lamina affects shear stress on smooth muscle cells (3D simulations). American Journal of Physiology 2002, 282:H576-584.

26. Tardy Y, Resnick N, Nagel T, Gimbrone MA, Dewey CF: Shear stress gradients remodel endothelial monolayers in vitro via a cell proliferation-migration-loss cycle. Arterioscler Thromb Vasc Biol 1997, 17:3102-3106

27. Lei M, Kleinstreuer C, Truskey GA: A focal stress gradientdependent mass transfer mechanism for atherogenesis in branching arteries. Med Eng Phys 1996, 18:326-332.

28. Ku DN, Giddens DP, Zarins CK, Glagov S: Pulsatile flow and atherosclerosis in the human carotid bifurcation. Positive correlation between plaque location and low oscillating shear stress. Arteriosclerosis 1985, 5:293-302.

29. Ku DN: Blood flow in arteries. Annu Rev Fluid Mech 1997, 29:399-434.

30. Finol EA, Amon $\mathrm{CH}$ : Blood flow in abdominal aortic aneurysms: pulsatile flow hemodynamics. J Biomech Eng 200I, I 23:474-484.

31. Ojha M: Spatial and temporal variations of wall shear stress within an end-to-side arterial anastomosis model. J Biomech 1993, 26:1377-1388.

32. Kute SM, Vorp DA: The effect of proximal artery flow on the hemodynamics at the distal anastomosis of a vascular bypass graft: computational study. J Biomech Eng 200I, I 23:277-283.

33. Lei M, Kleinstreuer C, Archie JPJ: Geometric design improvements for femoral graft-artery junctions mitigating restenosis. J Biomech 1996, 29:1605-1614.

34. Myers JG, Moore JA, Ojha M, Johnston KW, Ethier CR: Factors influencing blood flow patterns in the human right coronary artery. Annals of Biomedical Engineering 200I, 29:I09-I20.

35. LaDisa JFJ, Guler I, Olson LE, Hettrick DA, Kersten JR, Warltier DC Pagel PS: Three-dimensional computational fluid dynamics modeling of alterations in coronary wall shear stress produced by stent implantation. Ann Biomed Eng 2003, $31: 972-980$

36. Murata T, Hiro T, Fujii T, Yasumoto K, Murashige A, Kohno M, Yamada J, Miura T, Matsuzaki M: Impact of the cross-sectional geometry of the post-deployment coronary stent on in-stent neointimal hyperplasia: an intravascular ultrasound study. Circ J 2002, 66:489-493.

37. Wentzel Jj, Whelan DM, van der Giessen WJ, van Beusekom HM, Andhyiswara I, Serruys PW, Slager CJ, Krams R: Coronary stent implantation changes 3-D vessel geometry and 3-D shear stress distribution. Journal of Biomechanics 2000, 33: I 287-I 295.

38. LaDisa JFJ, Meier HT, Olson LE, Kersten JR, Warltier DC, Pagel PS: Antegrade iliac artery stent implantation for the temporal and spatial examination of stent-induced neointimal hyperplasia and alterations in regional fluid dynamics. Journal of Pharmacological and Toxicological Methods 2005, 5 I:I I5-121.

39. LaDisa JFJ, Olson LE, Ropella KM, Molthen RC, Haworth ST, Kersten JR, Warltier DC, Pagel PS: Microfocal x-ray computed tomography post-processing operations for optimizing reconstruction volumes of stented arteries during 3D computational fluid dynamics modeling. Computer Methods and Programs in Biomedicine 2005, 79:121-134.

40. Perktold K, Rappitsch G: Computer simulation of local blood flow and vessel mechanics in a compliant carotid artery bifurcation model. Journal of Biomechanics 1995, 28:845-856.

4I. Finn AV, Palacios IF, Kastrati A, Gold HK: Drug-eluting stents for diabetes mellitus: a rush to judgment? J Am Coll Cardiol 2005, 45:479-483

42. Palmaz JC: Intravascular stents in the last and the next 10 years. J Endovasc Ther 2004, Suppl 2:I1200-206.

43. Virmani R, Farb A, Guagliumi G, Kolodgie FD: Drug-eluting stents: caution and concerns for long-term outcome. Coronary Artery Disease 2004, I 5:313-318.

44. Virmani R, Kolodgie FD, Farb A, Lafont A: Drug eluting stents: are human and animal studies comparable? Heart 2003, 89:133-138. 